\title{
Antibodies for Sars Cov 2 in Infant Children of Mothers Vaccinated Against Covid19
}

Néstor Fabián Sanabria Duarte, Luis Esteban García Jiménez, María Paula Vallejo Tapias, María Alejandra Suta Figueroa, María Cristina Suárez Gómez, Marggy Stephania Sáenz Gómez and Andrea Ximena Carvajal Mejía 'Intern Physician, Universidad Autónoma de Bucaramanga, Colombia

${ }^{2}$ General Physician, Escuela Superior Politécnica de Chimborazo

${ }^{3}$ Student Physician, Universidad Autónoma de Bucaramanga, Colombia

4Intern Physician, Universidad Autónoma de Bucaramanga, Colombia

Intern Physician, Universidad Autónoma de Bucaramanga, Colombia

'Intern Physician, Universidad Autónoma de Bucaramanga, Colombia

'Intern Physician, Universidad Autónoma de Bucaramanga, Colombia

*Corresponding author: Néstor Fabián Sanabria Duarte, Intern Physician, Universidad Autónoma de Bucaramanga, Colombia

\section{ABSTRACT}

Since the beginning of the covid-19 pandemic, there have been multiple unknowns to be solved about this new disease, one of these has been the process to generate a vaccine, obtaining in 2020 the first vaccines, new doubts arise such as what special considerations pregnant women will have regarding vaccination and if there is the possibility of transferring antibodies from the newborn mother through the placenta, The current scientific evidence reflects that there is the possibility of transferring antibodies against covid-19 in infants whose mothers have been previously vaccinated against this disease, based on studies of serum, breast milk and umbilical cord, with positive findings about the presidency of these antibodies and the possibility of their existence in infants born to these mothers.

KEYWORDS: Antibodies; covid 19; vaccines

\section{INTRODUCTION}

The current SARS VOC 2 pandemic is having a huge impact around the world; started in Wuhan, China, in December 2019 causing the COVID-19 disease. This is primarily a respiratory illness that presents with symptoms including fever, cough and shortness of breath, which can progress to respiratory failure, this can present with a wide spectrum of symptoms including sore throat, headache, loss of taste or smell, nausea, vomiting and diarrhea [1,2]. The groups most vulnerable to presenting serious disease and complications are those over 60 years of age, people with coexisting diseases such as high blood pressure, cardiovascular disease, diabetes mellitus, lung disease, obesity, kidney disease, neoplasms and pregnant women, among others. $[1,2,3]$

Pregnant women are in a higher risk group for acquiring respiratory diseases due to the series of physiological changes that occur in pregnancy, such as increased oxygen demand, elevated diaphragm, among others. $[4,6,7]$
There is a series of pathologies where there is the possibility of maternal-fetal transmission, such as HIV, influenza, toxoplasmosis, and the possible maternal-fetal transmission of Covid -19 has been investigated $[5,7]$

As a result of this, the efforts by the World Health Organization have been aimed at the production of a vaccine, in order to prevent the transmission and the severity of the clinical picture, the scientific literature shows the possibility of transmission of antibodies through the placenta not only for covid-19 disease. $[8,9,10]$.

Vaccines are designed to prevent different diseases such as chickenpox, hepatitis, meningitis, influenza, among others. When a pregnant woman receives a dose of any vaccine, there is the possibility of transferring antibodies from mother to fetus, since there is scientific evidence that shows us antibodies present in newborns whose mothers received some type of vaccine. The objective of this study is to review the presence of antibodies to SARS COV 2 in 
infants of mothers vaccinated against COVID 19.

\section{MATERIALS AND METHODS}

A bibliographic search was carried out in different databases, highlighting PUBMED, SCIENCE DIRET, SCIELO, OVID, SCHOLAR GOOGLE, from 2015 to 2021 our keywords were: antibodies, Covid-19, Pregnant, Lactating, Vaccines. The initial results showed a total of 125 studies, of which those works published in any language other than English or Spanish and those that did not have full text available were excluded, thus we have a total of 15 articles for our review, highlighting reviews, meta-analysis, clinical trials, systematic reviews, later the studies found were read, which describes physiological and anatomical aspects in pregnancy, the physiology of the maternal-fetal immune response, the different mechanisms with which vaccines generate antibodies and how these antibodies can be transmitted from mother to infant.

\section{RESULTS}

Pregnancy and its relationship with Covid-19. Pregnant women are particularly prone to respiratory pathogens, such as SARS-CoV-2, due to physiological changes during pregnancy; the increase in oxygen demand and the elevation of the diaphragm, for this reason it is explained that pregnant women are susceptible to hypoxia, the first data do not indicate that pregnant women have a greater risk of morbidity, but they do indicate a greater risk of admission and ventilation in the ICU. Furthermore, due to the increased concentration of ACE2 receptors in the placenta, there is concern about the possibility of vertical transmission from mother to child. In fact, case studies have shown that SARS-CoV-2 can infect the placenta. (figure 1) $[2,5,6]$.

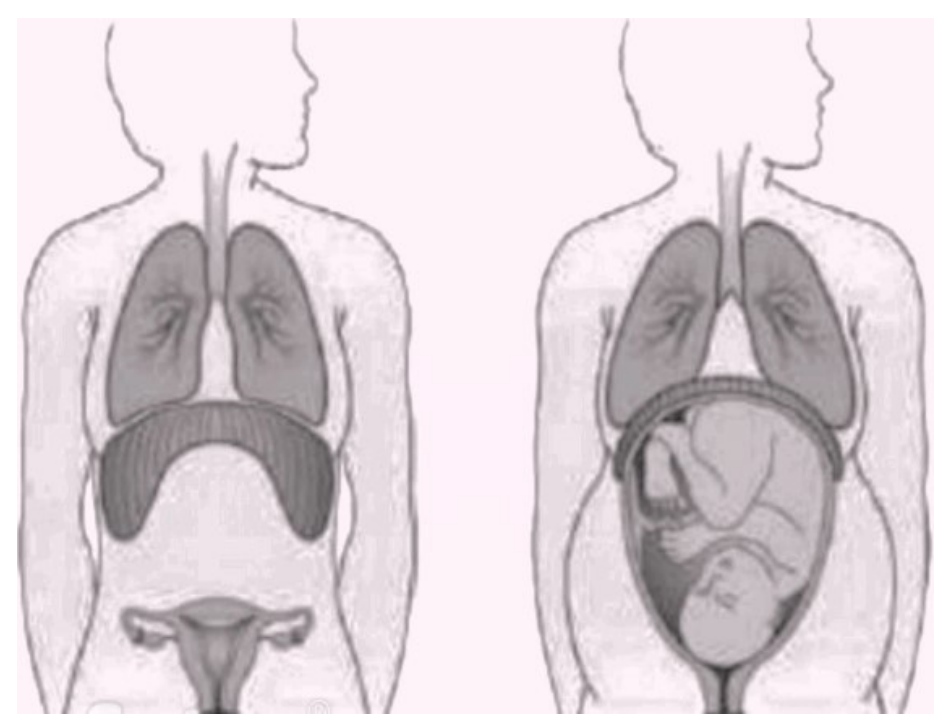

Figure1: Anatomical changes in pregnancy

\section{Maternal-Fetal Antibodies}

The placenta plays an important role that intervenes in the interaction of the mother and the developing fetus, this is a multifaceted organ, among the crucial functions of this organ to protect the fetus from the maternal immune response in order to prevent it from being rejected by the same, in addition this conditions the transfer of maternal antibodies. It is worth noting that the fetus represents a graft once implanted in the mother, since it produces foreign proteins for the maternal immune system, capable of being synthesized by the genetic information that the father provides, therefore a compatibilizer mechanism intervenes that inhibits the rejection of the fetus, which is caused by various factors such as immunosuppressants and modulators from the placenta $[4,5]$.

Immunity is considered as a set of integrated processes or mechanisms that play an important role in our body's defense response to different foreign agents, whether internal or external, to which we are exposed [2]. In the uterus, the fetus is protected by the mother from all external agents, therefore it does not need a functioning immune system. Once outside, the fetus has a complete but immature immune system, even so, it is capable of responding to antigenic stimuli. Maternal immunity provides maternal immune cells and antibodies that are capable of protecting newborns, but temporarily, this transfer of antibodies can be carried out by the placenta in the prenatal stage, by colostrum and in breast milk $[4,5,6]$.

In the fetus, the immune system is given by the cells that are derived from the precursor cells of the hematopoietic system, which until the third fetal week come from the germ sac, in the eighth week of the fetal liver and after the fifth month of gestation is given by the bone marrow. All these cells carry out different processes in order to create an innate and adaptive immune system. In weeks 9-10 of gestation, innate immunity begins complement synthesis and NK cells can be found in the liver. In weeks 12-14, humoral immunity presents pre-B cells with IgD, IgG and $\lg A$, and in this stage the passive transfer of maternal IgG begins. Between weeks 20-30, in humoral immunity, B cells secrete antibodies and transplacental transport of IgG gradually increases. Taking into account the above, with regard to fetal life, serum immunity during is limited to the transfer of maternal IgG that has the ability to reach the fetal circulation, and that is why newborns only have a limited percentage of antibodies. This immunoglobulin has the competence to cross the placental barrier, primarily in the last trimester of pregnancy where its percentage in circulation increases $[4,5,7]$.

Citation: Néstor Fabián Sanabria Duarte, Luis Esteban García Jiménez, María Paula Vallejo Tapias, María Alejandra Suta Figueroa, María

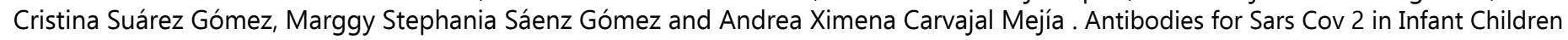
of Mothers Vaccinated Against Covid19.

Op Acc J Bio Sci \& Res 10(1)-2021 
In this way, it can be explained how maternal antibodies give neonates partial protection against various viral infections; however, so far there is very little knowledge of the perinatal humoral immune response to SARS-CoV-2 [2]. A study carried out in China set out to describe the dynamic changes in antibody levels in 6 newborns of mothers who developed coronavirus disease during the second and third trimesters of pregnancy. It was found that the 6 of the patients who suffered from the infection in the second and third trimesters presented different immune responses. Of the three patients infected with SARS-CoV-2 in the third trimester they showed positive results in the PCR, in addition that levels of IgG and IgM were detected until the moment of delivery, while the neonates of these mothers did not have viral results positive, but I did have detectable IgG at delivery, and one had IgM. In both three women infected in the second trimester and their newborns, SARSCoV-2 nucleic acids were not found at the time of delivery, but specific IgG for the virus was detected, but not IgM. It was also found that after delivery, women infected in the second trimester and their children had a long-lasting IgG response compared to those infected in the third trimester and their children. The conclusion reached in the study was that it was found that those asymptomatic infants who were born to mothers infected with COVID-19 in the second trimester of pregnancy have a stronger immune response. This could be explained by the above, by the transfer of IgG from the mother to the fetus through the placenta, which begins at the end of the second trimester and reaches its highest levels in the third trimester at the time of delivery $[3,4,5,6]$.

\section{Antibodies Against Covid -19 And Infants.}

Since the beginning of the pandemic caused by the SARS COV 2 virus, there have been many attempts to produce a vaccine that is highly effective against it and that manages to generate an immunity that lasts over time and manages to combat the different variants. Among these, multiple mechanisms of action stand out that will eventually lead to the production of antibodies, (Table 1) $[8,9]$.

All of these ultimately what they seek is to induce an active immunity similar to that caused by infection, but without contracting it. This virus has multiple proteins; which cause an immune response in the host mediated by CD4 and CD8 T lymphocytes together with the production of specific neutralizing antibodies. The CD4 T lymphocyte response against protein $S$ is one of the largest and is consistent with the magnitude of IgA and IgG titers. This $S$ protein plays a fundamental role in the development of vaccines since it helps the virus to bind to the receptors of
Table1: Main mechanisms of vaccine antibody production

\begin{tabular}{|c|c|}
\hline Mechanism of Immunity & Vaccine \\
\hline $\begin{array}{c}\text { RNA or DNA: material that is } \\
\text { genetically modified to produce a } \\
\text { protein that triggers an immune } \\
\text { response. }\end{array}$ & $\begin{array}{c}\text { 1. Pfizer } \\
\text { Biontech }\end{array}$ \\
\cline { 2 - 2 } $\begin{array}{c}\text { Viral vectors: genetically modified } \\
\text { virus that generates viral corona } \\
\text { proteins that induce an immune } \\
\text { response. }\end{array}$ & 1. AstraZeneca \\
\cline { 2 - 2 } & 2. Johnson \& \\
\hline $\begin{array}{c}\text { Proteins: harmless protein fragments } \\
\text { or protein structures that mimic the } \\
\text { virus that causes Covid-19 }\end{array}$ & Johnson \\
\hline $\begin{array}{c}\text { inactivated or attenuated viruses: } \\
\text { harmless protein fragments or protein } \\
\text { structures that mimic the virus that } \\
\text { causes Covid-19 }\end{array}$ & \\
\hline
\end{tabular}

the Angiotensin Converting Enzyme (ACE 2), therefore, it is attractive for the creation of vaccines $[9,10,11]$.

Recommendations from different organisms have justified the efficacy and safety of these vaccines in pregnant patients and during the lactation period, in addition to the fact that it has been proven that they could also produce temporary immunity in the newborn [3]. The prospective cohort study carried out by Gray et al in which a total of 131 women of reproductive age who received messenger RNA vaccines against SARS CoV 2 were included, 84 of them were pregnant, 31 were lactating, 16 were not pregnant, and from whom serum samples were taken from 10 of them, samples were also taken from the umbilical cord, and from breast milk to study IgG, IgM and IgA titers; found that these antibodies were found in all samples taken from both umbilical cord and breast milk, although in the umbilical cord sample they were lower than in the maternal serum sample, the difference was not significant; Immune transfer to newborns was also shown to occur through the placenta and breast milk [4]. On the other hand, the prospective cohort study carried out by Perl et al and in which a sample of 84 women of breast milk was taken after vaccination with Pfizer BioNTech and who were studied for the presence of IgA and IgG antibodies, showed that after 6 weeks after vaccination, these antibodies were still being secreted in breast milk; the antibodies found in the breast milk of these women showed strong neutralizing effects, suggesting a

Citation: Néstor Fabián Sanabria Duarte, Luis Esteban García Jiménez, María Paula Vallejo Tapias, María Alejandra Suta Figueroa, María Cristina Suárez Gómez, Marggy Stephania Sáenz Gómez and Andrea Ximena Carvajal Mejía . Antibodies for Sars Cov 2 in Infant Children of Mothers Vaccinated Against Covid19.

Op Acc J Bio Sci \& Res 10(1)-2021 
possible protective effect against infection in the infant [13].

Although the information available about studies carried out in infants is very limited due to the ethical implications that studying newborns brings, it is important to highlight the studies carried out in mothers who are breastfeeding since current evidence reflects the possibility of transmission of antibodies against covid-19 already being vaccinated, it has been possible to obtain information about studies carried out in breast milk, serum and umbilical cord, giving as a positive finding the presence of antibodies against covid-19 in these samples suggesting a possible transmission to the newborn born, providing immune protection during the first weeks of life against this disease $[4,6]$.

\section{DISCUSSION}

Multiple studies have been carried out in order to study the effectiveness of vaccines by studying the production of antibodies over time. As is the case of the study carried out by the Bogotá district health secretariat, in which 241 (of which 41 were excluded because they were seropositive prior to the application of the vaccine) patients who were vaccinated with the biological Pfizer- BioNTech and who underwent a semi-quantitative study of total Ig and specific IgG for SARS CoV 2, resulting in that at three weeks after the application of the first dose, $95 \%$ and $96 \%$ of the immunized individuals, show reactivity for total Ig and IgG, anti-S, respectively, evidencing the appearance of antibodies in this sample, which is not far from the results obtained in our investigation $[14,16]$.

The objective of our study was to describe the antibodies to sars cov 2 in infants of mothers vaccinated against covid-19, thus finding that if samples from mothers vaccinated against covid-19 are studied, whether serum, breast milk or even umbilical cord, there are positive data about the transmission of antibodies, which suggests the possibility of the presence of antibodies in newborns and possible immunological protection against Covid-19, comparing these results with information obtained in other studies that look for the immune response in newborns faced with different diseases, such as the flu or influenza, we have the study carried out by Shabir and collaborators where they carried out a study characterized by double-blind randomized controlled trials, where 2116 HIV-uninfected women included 194 HIV-infected women using placebo and inactivated trivalent influenza vaccine (IIV3) evaluating immunoglobulin enicity, safety and efficacy of the vaccine in pregnant women and their babies up to 24 weeks after birth, measuring immune responses using hemagglutination assays and PCR testing, finding that the influenza vaccine was immunogenic in both infected and non-infected pregnant women infected by HIV, presenting a partial proportion of protection against confirmed influenza in both groups and in babies, thus evidencing the transmission of antibodies from the mother to the fetus and providing immunity in the first weeks of life, when comparing these results with our research, we can investigate that there is a particular mechanism of transmission of maternal-fetal antibodies for various vaccines $[12,14,15]$.

\section{CONCLUSION}

We conclude that there is the presence of antibodies against covid-19 in infants whose mothers have been previously vaccinated against this disease, this always when breast milk or umbilical cord serum is studied, suggesting the presence of antibodies in infants in the first weeks of life, further studies are recommended to deepen these findings.

\section{References}

1. Neumosur (2020). Documento General COVID-19. Asociación de Neumología y Cirugía Torácica del Sur, 2020.

2. Diaz C, Gonzalez G, Maryla Y Lopez HI. COVID-19 en Pediatría. ¿Qué se sabe? Rev haban cienc méd [online]. 2021, 20(1): e3637.

3. H Harapana, Naoya I, A Yufika, W Winardif, S Keamg, et al. Coronavirus disease 2019 (COVID-19): A literature review. Journal of Infection and Public Health, 2020; 13(5): 667-673

4. Zhang C, Chu H, Pei YV, Zhang J. Laboratory effects of COVID-19 infection in pregnant women and their newborns: A systematic review and metaanalysis. Front Glob Women's Health, 2020; 2: 647072.

5. Auad J, Cerutti J, Cooper GL, Lozano N, Deltrozzo J, et al. Estructura de la placenta y su impacto en la transferencia de la inmunidad materno-fetal. revisión en mamíferos domésticos. Rev Methodo, 2018; 4(2): 52-62.

6. Huaheng Mo, Ming Wang, Mengmei Wang, Yi Han. Detectable antibodies against SARS-CoV-2 in newborns from mothers infected with COVID-19 at different gestational ages. Pediatrics and Neonatology, 2021; 62(3): $321 \mathrm{e} 323$.

7. Salazar Torres, D Ávila Gamboa. (2014, 5 agosto). Inmunología perinatal. Inmunología perinatal. Universidad de Ciencias Médicas de Villa Clara-Cuba.

8. O Limay Ríos, C Dávila Aliaga, R Álvarez Carrasco, M Espinola Sánchez. Transmission Perinatal de SARS-COV-2: Necesidad de Estudio Ante Posible Infeccion Congenita. Transmission Perinatal de SARS-COV-2. (2020, 5 septiembre).

9. Vacunas SARS-COV2 marzo 2021. Nefrologiaaldia.

10. Vacunas contra COVID-19 Bvsalud.org. [ octubre de 2021].

11. CDC. Consideraciones de vacunación para personas embarazadas y en periodo de lactancia Cdc.gov. 7, 2021.

12. G Izquierdo, D Martíneza. Revista médica clínica las condes. Vacunas e inmunizaciones En recién nacidos y recién nacidos prematuros. (2020, 12 abril).

13. Gray KJ, Bordt EA, Atyeo C, Deriso E, Akinwunmi B, et al. Coronavirus disease 2019 vaccine response in pregnant and lactating women: a cohort study. Am J Obstet Gynecol, 2021; 225(3): 303.e1-303.e17.

14. Perl SH, Uzan Yulzari A, Klainer H, Asiskovich L, Youngster M, et al. SARS-CoV-2-specific antibodies in breast milk after COVID-19 vaccination of breastfeeding women. JAMA, 2021; 325(19): 2013-2014.

15. Shabir A, Madhi, Clare L, Cutland, Locadiah Kuwanda, et al. Influenza vaccination of pregnant women and protection of their infants, 2015; 371(10): 918-931.

16. Inmunovigilancia: Evaluación de la inmunogenicidad de las vacunas anti-COVID-19 en el marco de la farmacovigilancia intensiva-Protocolo Bogotá, Distrito Capital Formulación Pfizer/BioNTech. saludcapital.gov. co. 2021.

Citation: Néstor Fabián Sanabria Duarte, Luis Esteban García Jiménez, María Paula Vallejo Tapias, María Alejandra Suta Figueroa, María Cristina Suárez Gómez, Marggy Stephania Sáenz Gómez and Andrea Ximena Carvajal Mejía . Antibodies for Sars Cov 2 in Infant Children of Mothers Vaccinated Against Covid19. 